\title{
Magnifying Endoscopy in a Patient With Chest Pain and Dysphagia
}

\author{
Gwang Ha Kim \\ Department of Internal Medicine, Pusan National University School of Medicine, Busan, Korea
}

A 42-year-old male patient presented with atypical chest pain and dysphagia for 2 months. There were no abnormal findings in previous cardiac evaluations. Two weeks before, he underwent the upper endoscopy in a local clinic and the result was negative. Under the suspicion of an eosinophilic esophagitis, we planned to perform the upper endoscopy again with esophageal random biopsies. If the result was negative, the esophageal motility test and impedance/pH test were considered for the following step.

On the upper endoscopy, the typical findings of eosinophilic esophagitis such as mucosal rings, furrows or whitish plaques were not seen. Also, there was no definite mucosal break on lower esophagus by conventional endoscopy (Figure A) and narrow band imaging (NBI) endoscopy (Figure B). However, after magnifying the esophagogastric junction by GIF-H260Z (Olympus Medical Systems Corp, Tokyo, Japan), a tiny mucosal break was seen on lower esophagus just above the Z-line (Figure C). Increased vascularity was also observed. On esophageal biopsies, the number of eosinophils was not increased. These findings led to the diagnosis of reflux esophagitis. Chest pain and dysphagia subsided with the treatment of esomeprazole for 2 months. Con-
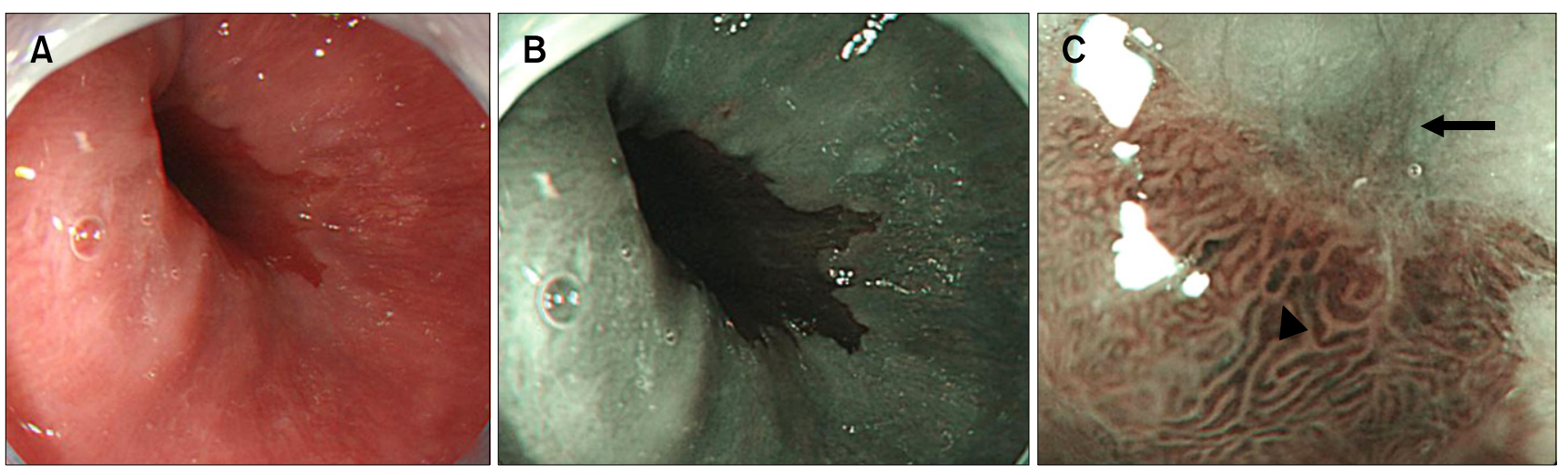

Figure. There is no definite abnormal finding on the esophagogastric junction by conventional endoscopy (A) and NBI endoscopy (B). After being magnified by GIF-H260Z, a tiny mucosal break (arrow) and increased vascularity (arrow head) are seen on the esophagogastric junction (C).

Received: November 2, 2010 Revised: None Accepted: November 14, 2010

(c) This is an Open Access article distributed under the terms of the Creative Commons Attribution Non-Commercial License (http://creativecommons. org/licenses/by-nc/3.0) which permits unrestricted non-commercial use, distribution, and reproduction in any medium, provided the original work is properly cited.

*Correspondence: Gwang Ha Kim, MD

Department of Internal Medicine, Pusan National University School of Medicine, 1-10 Ami-dong, Seo-gu, Busan 602-739, Korea Tel: +82-51-240-7869, Fax: +82-51-244-8180, E-mail: doc0224@pusan.ac.kr

Financial support: None.

Conflicts of interest: None. 
ventional endoscopy appears to be an insensitive test for diagnosis of gastroesophageal reflux disease (GERD) because fewer than $40 \%$ of patients complaining heartburn and regurgitation exhibit endoscopic abnormalities. ${ }^{1} \mathrm{NBI}$ enables detailed inspection of the mucosal and vascular surface patterns without the use of staining agents. A prospective study in patients with GERD showed that magnifying endoscopy with NBI represented a significant improvement over standard endoscopy for the diagnosis of GERD. ${ }^{2}$ Patients with GERD were likely to demonstrate microerosions and increased vascularity at the squamo-columnar junction. However, there have been a few reports on the usefulness of magnifying endoscopy with NBI in the patients with GERD. ${ }^{3,4}$ Therefore, further prospective studies are needed to define the role of magnifying endoscopy with NBI in diagnosing reflux esophagitis.

\section{References}

1. Dent J, Armstrong D, Delaney B, Moayyedi P, Talley NJ, Vakil N. Symptom evaluation in reflux disease: workshop background, processes, terminology, recommendations, and discussion outputs. Gut 2004;53(suppl 4):iv1-iv24.

2. Sharma P, Wani S, Bansal A, et al. A feasibility trial of narrow band imaging endoscopy in patients with gastroesophageal reflux disease. Gastroenterology 2007;133:454-464.

3. Fock KM, Teo EK, Ang TL, Tan JY, Law NM. The utility of narrow band imaging in improving the endoscopic diagnosis of gastroesophageal reflux disease. Clin Gastroenterol Hepatol 2009;7:54-59.

4. Tseng PH, Chen CC, Chiu HM, et al. Performance of narrow band imaging and magnification endoscopy in the prediction of therapeutic response in patients with gastroesophageal reflux disease. J Clin Gastroenterol Published Online First: 20 Aug 2010. doi:10.1097/ MCG.0b013e3181eeb115 